\title{
Clinical outcomes of submucosal colorectal cancer diagnosed after endoscopic resection: a focus on the need for surgery
}

\author{
Yun Sik Choi ${ }^{1}$, Wan Soo Kim² ${ }^{2}$ Sung Wook Hwang ${ }^{1}$, Sang Hyoung Park ${ }^{1}$, Dong-Hoon Yang ${ }^{1}$, Byong Duk Ye ${ }^{1}$, \\ Seung-Jae Myung ${ }^{1}$, Suk-Kyun Yang ${ }^{1}$, Jeong-Sik Byeon ${ }^{1}$ \\ ${ }^{I}$ Department of Gastroenterology, Asan Medical Center, University of Ulsan College of Medicine, Seoul; ${ }^{2}$ Department of Internal Medicine, \\ Gyeongsang National University Changwon Hospital, Changwon, Korea
}

Background/Aims: We aimed to investigate the proportion of and risk factors for residual cancer and/or lymph node metastasis after surgery was performed because of high-risk pathological features in endoscopic resection specimen of suspected superficial submucosal colorectal cancer (SSMC). Methods: We reviewed medical records of 497 patients (58.8 \pm 9.8 years, 331 males) undergoing endoscopic resection of suspected SSMC. High-risk pathological features included: deep submucosal cancer invasion $\geq 1,000 \mu \mathrm{m}$; positive lymphovascular and/or perineural invasion; poorly differentiated adenocarcinoma; and positive resection margin. We investigated the occurrence of additional surgery and residual cancer and/or lymph node involvement in the surgical specimen. Results: En bloc resection was performed in 447 patients (89.9\%). High-risk pathological features were detected in 372 patients (74.8\%). Additional surgery was performed in 336 of 372 patients with high-risk pathological features. Of these, 47 surgical specimens (14.0\%) showed residual cancer and/or lymph node metastasis. Piecemeal resection was more common in those with residual cancer and/or lymph node involvement than those without (9/47 [19.1\%] vs. $24 / 289$ [8.3\%], $P=0.032$ ). Positive resection margin was also significantly associated with positive residual cancer and/or lymph node involvement. As the number of high-risk pathological features increased, the risk of regional lymph node metastasis increased proportionally $(P=0.002)$. Conclusions: High-risk pathological features were frequently detected after endoscopic resection of suspected SSMC while residual cancer and/or lymph node metastasis were not commonly present in the additional surgical specimen. Further optimized strategy for proper endoscopic management of suspected SSMC is necessary. (Intest Res 2020;18:96-106)

Key Words: Submucosal colorectal cancer; Endoscopic resection; Surgery

\section{INTRODUCTION}

The incidence of colorectal cancer has been increasing worldwide. ${ }^{1}$ Most colorectal cancers originate from precancerous polyps. ${ }^{2}$ Therefore, to decrease mortality, it is extremely important to identify precancerous polyps or early colorectal

Received August 8, 2019. Revised December 14, 2019.

Accepted December 16, 2019.

Correspondence to Jeong-Sik Byeon, Department of Gastroenterology,

Asan Medical Center, University of Ulsan College of Medicine, 88 Olympic-ro

43-gil, Songpa-gu, Seoul 05505, Korea. Tel: +82-2-3010-3905, Fax: +82-2-

3010-6157,E-mail: jsbyeon@amc.seoul.kr cancer by routine screening tests and to then treat them to block further development into advanced colorectal cancer. Thus, clinical practice guidelines suggest various screening tests including colonoscopy. ${ }^{3-5}$ Colonoscopy is especially useful due to its ability to detect and treat precancerous polyp and early colorectal cancer. ${ }^{6}$

Of early colorectal cancers, superficial submucosal colorectal cancer (SSMC) defined by the depth of invasion from muscularis mucosa as less than $1,000 \mu \mathrm{m}$, can be completely cured by endoscopic resection if it does not have any adverse pathologic findings including poorly differentiated adenocar- 
cinoma and lymphovascular invasion or tumor budding. ${ }^{7-11}$ If these indications are followed, there is no difference in longterm outcomes between endoscopic resection and surgery in SSMC. ${ }^{12}$ In situations where a deep submucosal cancer (DSMC) with a depth of more than $1,000 \mu \mathrm{m}$, poor pathologic prognostic features such as poor differentiation or lymphovascular invasion, and presence of positive resection margin, the possibility of regional node involvement or residual cancer cannot be ruled out, so it is recommended to add surgery to remove the residual cancer or regional lymph nodes involved by cancer. ${ }^{13}$

To minimize the need for additional surgery, accurately estimating whether the early cancer is either SSMC or DSMC is crucial because the SSMC requires only endoscopic resection, while DSMC is treated by surgery. Endoscopic observation including dye chromoscopy and image enhanced endoscopy such as narrow band imaging (NBI) is used to identify the possibility of SSMC or DSMC before endoscopic resection. ${ }^{14-17}$ Despite these various examination methods, it is not uncommon that lesions initially predicted as SSMC is ultimately diagnosed as DSMC and/or cancer with poor pathologic prognostic features after endoscopic resection thereby necessitating additional surgery. ${ }^{18}$ Furthermore, it is also not uncommon that surgical specimens of DSMC and/or cancer with poor pathologic features show no regional lymph metastasis nor residual cancer thereby raising a question whether additional surgery would have been really necessary.

Our study aimed to investigate the frequency of receiving surgery after endoscopic resection of suspected SSMC by analyzing the pathological diagnosis of the endoscopically resected specimen. We also aimed to evaluate the frequency and risk factors of regional lymph node metastasis or residual cancer in surgical specimens by reviewing the pathology reports. Furthermore, we tried to validate the overall long-term prognosis of presumed SSMC that is treated by endoscopic resection.

\section{METHODS}

\section{Patients}

From June 1996 to June 2015, we retrospectively reviewed the medical records of patients at Asan Medical Center who underwent endoscopic resection for $\mathrm{Tl}$ early cancer initially presumed as SSMC, followed by endoscopy, abdominal pelvic $\mathrm{CT}$ and chest radiography imaging. We presumed a tumor as suspected SSMC if the tumor showed type VI Kudo pit pattern and/or JNET (Japan NBI Expert Team) 2B NBI pattern without definite evidence of deep ulcer and non-lifting sign. A suspected SSMC assessed by these endoscopic features was managed initially by endoscopic resection. The following patients were excluded: (1) patients who had at least one previous colorectal cancer; (2) patients with cancers in other sites in addition to colorectum; (3) patients who underwent endoscopic resection followed by transanal surgical resection or radiation therapy; (4) patients without pathological reports because treatment occurred at outside hospital; and (5) patients with follow-up of less than 1 year after the procedure. This study was conducted with the approval of the Institutional Review Board of Asan Medical Center in Seoul (IRB No. 2016-0085). This study is a retrospective study using medical record review and so informed consent was waived.

\section{Endoscopic Resection}

Endoscopic resection for all SSMC lesions was performed by board-certified GI endoscopists who were highly specialized for therapeutic colonoscopy procedures. SSMC was estimated by white light endoscopy and examination of pit pattern through chromoscopy after indigocarmine spray. From 2008 onwards, analysis of the surface vascular pattern using NBI has been helpful for estimating the presence of SSMC. Endoscopic mucosal resection and/or endoscopic submucosal dissection were used, depending on the location, shape, and size of the lesion. En bloc resection was tried whenever possible. Lesion location was classified as proximal colon, distal colon, or rectum. Proximal colon included the cecum, ascending colon, hepatic flexure, and transverse colon; and the distal colon included splenic flexure, descending colon, and sigmoid colon.

\section{Histopathological Review and Additional Surgery}

Histopathologic examination of endoscopic resection specimens was used to determine invasion depth of cancer, differentiation, lymphovascular invasion, and status of lateral and deep resection margins. (1) DSMC (depth of submucosal cancer invasion $\geq 1,000 \mu \mathrm{m}$ or SM2 or SM3), (2) positive lymphovascular invasion, and (3) poorly differentiated adenocarcinoma, signet ring cell carcinoma, or mucinous carcinoma, (4) positive or indeterminate resection margins were defined as high-risk pathological features according to Japanese Society for Cancer of the Colon and Rectum and European Society of Gastrointestinal Endoscopy guidelines. In the present study, perineural invasion was also defined as high-risk pathology. ${ }^{19,20}$ Patients who showed endoscopic resection specimens with any of the highrisk pathologic findings were recommended to undergo surgi- 
cal resection with lymph node dissection. In some cases of SSMC without high-risk findings, surgery was also performed depending on the preference of patients and medical staff.

After surgery, histopathologic examination of the surgical specimens was used to confirm the presence of residual cancer in the endoscopic resection site and regional lymph node involvement.

\section{Review of Clinical Course}

Patients' medical records were reviewed retrospectively. The starting point of follow-up was the time of endoscopic resection, and the patient's age was the age at the time of endoscopic resection. We reviewed follow-up medical records until September 2017, including endoscopic, abdominopelvic CT and chest radiography results. Through this, we identified recurrence and death. Recurrence-free survival was defined as the time from the endoscopic resection until the confirmation of colorectal cancer recurrence. Recurrence was classified as local and metastatic recurrence. Local recurrence was defined as recurrence at the previous endoscopic resection site, as confirmed by endoscopic biopsy. Metastatic recurrence was defined as lymph node metastasis and/or metastasis to distant organs such as liver, lung, and peritoneum. Overall survival was defined as the time until the confirmation of death after endoscopic resection.

\section{Statistical Analysis}

Continuous variables were analyzed using Student $t$-test or Mann-Whitney $U$-test. Categorical parameters were compared using the chi-square test or Fisher exact test. To examine independent risk factors, logistic regression was used. Variables that were statistically and clinically significant in the univariate analysis were included in the multivariate analysis. Cumulative overall and recurrence-free survival rates were analyzed with the Kaplan-Meier method. Comparisons of overall and recurrence-free survival rates were performed with the log rank test. $P<0.05$ in a two-sided test was considered statistically significant. All these statistical analyses were performed by the R version 3.5.1 (R Foundation for Statistical Computing, Vienna, Austria; https://www.r-project.org/).

\section{RESULTS}

\section{Baseline Characteristics}

The mean age of the 497 patients included in the study was 58.8 years old and $331(66.6 \%)$ were male. The mean size of
Table 1. Baseline Characteristics of Patients

\begin{tabular}{|c|c|}
\hline Variable & Value $(n=497)$ \\
\hline Age (yr) & $58.8 \pm 9.8$ \\
\hline \multicolumn{2}{|l|}{ Sex } \\
\hline Male & $331(66.6)$ \\
\hline Female & $166(33.4)$ \\
\hline Tumor size $(\mathrm{mm})$ & $19.3 \pm 10.8$ \\
\hline \multicolumn{2}{|l|}{ Tumor location } \\
\hline Proximal & $107(21.5)$ \\
\hline Distal & $235(47.3)$ \\
\hline Rectum & $152(30.6)$ \\
\hline Indeterminate & $3(0.6)$ \\
\hline \multicolumn{2}{|l|}{ Resection modality } \\
\hline EMR & $393(79.1)$ \\
\hline ESD & $104(20.9)$ \\
\hline \multicolumn{2}{|l|}{ Resection method } \\
\hline En bloc & 447 (89.9) \\
\hline Piecemeal & $50(10.1)$ \\
\hline \multicolumn{2}{|c|}{ Pathological features of resected specimen } \\
\hline \multicolumn{2}{|c|}{ Invasion depth of cancer } \\
\hline $\mathrm{SM}<1,000 \mu \mathrm{m}$ & $173(34.8)$ \\
\hline $\mathrm{SM} \geq 1,000 \mu \mathrm{m}$ & $254(51.1)$ \\
\hline SM, unknown & $70(14.1)$ \\
\hline \multicolumn{2}{|l|}{ Differentiation } \\
\hline Well & $235(47.3)$ \\
\hline Moderate & $254(51.1)$ \\
\hline Poor & $7(1.4)$ \\
\hline Unknown & $1(0.2)$ \\
\hline \multicolumn{2}{|c|}{ Lymphovascular invasion } \\
\hline Negative & $392(78.9)$ \\
\hline Positive & $72(14.5)$ \\
\hline Unknown & $33(6.6)$ \\
\hline \multicolumn{2}{|l|}{ Perineural invasion } \\
\hline Negative & $357(71.8)$ \\
\hline Positive & $5(1.0)$ \\
\hline Unknown & $135(27.2)$ \\
\hline \multicolumn{2}{|c|}{ Lateral resection margin } \\
\hline Negative & $415(83.5)$ \\
\hline Cancer & $40(8.0)$ \\
\hline Indeterminate & $42(8.5)$ \\
\hline \multicolumn{2}{|c|}{ Deep resection margin } \\
\hline Negative & $391(78.7)$ \\
\hline Cancer & $70(14.1)$ \\
\hline Indeterminate & $36(7.2)$ \\
\hline \multicolumn{2}{|c|}{ High-risk pathology in the endoscopic resection specimen } \\
\hline Absent & $125(25.2)$ \\
\hline Present & $372(74.8)$ \\
\hline
\end{tabular}

Values are presented as mean \pm SD or number (\%).

$E M R$, endoscopic mucosal resection; ESD, endoscopic submucosal dissection; SM, submucosa. 
early colorectal cancer in which SSMC was suspected was $19.3 \pm 10.8 \mathrm{~mm}$ (Table 1). Endoscopic mucosal resection was performed in 393 patients (79.1\%) and endoscopic submucosal dissection was performed in 104 patients (20.9\%). En bloc resection was performed in 447 patients (89.9\%) and piecemeal resection was performed in 50 patients (10.1\%).

When endoscopic resection specimens were examined, 173 patients (34.8\%) had submucosal invasion depth $<1,000$ $\mu \mathrm{m}$ of cancer. Well differentiated adenocarcinoma was identified in 235 patients (47.3\%) and poorly differentiated adenocarcinoma was identified in 7 patients (1.4\%). Positive lymphovascular invasion was observed in 72 patients (14.5\%). Positive cancer involvement in the lateral resection margin was identified in 40 patients (8.0\%) and 70 patients (14.1\%) had positive cancer involvement in the deep resection margin. As a result, $372(74.8 \%)$ had one or more high-risk pathological features. Of the 372 patients with high-risk pathological features, 336 underwent surgery and 27 of 125 patients without high-risk pathological features also underwent surgery (Fig. 1). There was no patient who underwent secondary endoscopic treatment in the group with high-risk pathology features.

\section{Clinical Outcomes during the Follow-up Period}

The mean follow-up period was $91.9 \pm 39.7$ months (range, 27-255 months) after endoscopic resection. Six out of $497 \mathrm{pa}-$ tients (1.2\%) had recurrence during the follow-up period. None out of 15 cecal lesions ( $0 \%$ ) showed recurrence. Recurrence developed in 1 (2.1\%) of 48 ascending colonic lesions, 0 $(0 \%)$ of 44 transverse colonic lesions, 1 (3.1\%) of 32 descending colonic lesions, 2 (1.0\%) of 203 sigmoid colonic lesions, and 2 (1.3\%) of 152 rectal lesions. Among the 98 patients without high-risk pathological features who did not undergo surgery, 1 patient $(0.8 \%)$ had recurrence. The patient had been treated not by en bloc resection but by piecemeal resection, and local recurrence of benign adenoma was confirmed during follow-up colonoscopy 7 months after endoscopic piecemeal resection (Table 2). No recurrence developed in 27 of 125 patients without high-risk features who underwent additional surgery because of patients' request based on their fear for cancer recurrence (Fig. 1). Among 372 patients with highrisk pathological features, 36 patients did not undergo surgery because of old age, underlying diseases, and fear for surgery. One of the 36 patients (2.8\%) had recurrence. Four out of 336 patients (1.2\%) who underwent surgery had recurrence.

There was no statistically significant difference in recur-

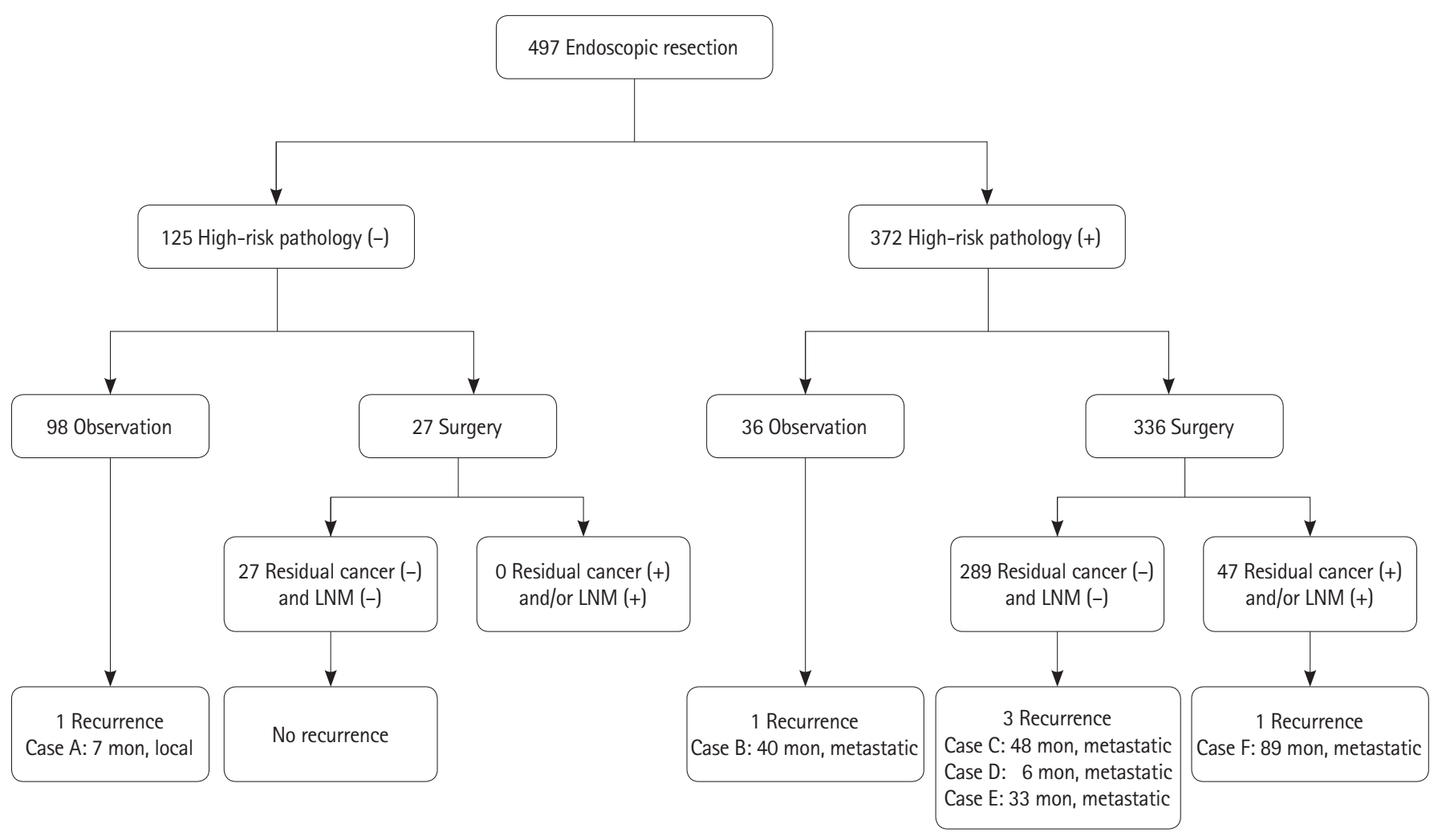

Fig. 1. Clinical outcome after endoscopic resection of suspected superficial submucosal cancer in 497 patients. LNM, lymph node metastasis. 
Table 2. Clinical Features of Recurrence Cases

\begin{tabular}{|c|c|c|c|c|c|c|c|c|c|c|}
\hline Case & $\begin{array}{c}\text { Sex/age } \\
(y r)\end{array}$ & Location & $\begin{array}{l}\text { Size } \\
(\mathrm{mm})\end{array}$ & $\begin{array}{r}\text { Resection } \\
\text { modality }\end{array}$ & $\begin{array}{c}\text { Resection } \\
\text { method }\end{array}$ & $\begin{array}{c}\text { No. of high-risk } \\
\text { pathological } \\
\text { features }\end{array}$ & $\begin{array}{l}\text { Additional } \\
\text { surgery }\end{array}$ & $\begin{array}{l}\text { Time to } \\
\text { recurrence } \\
\text { (mon) }\end{array}$ & $\begin{array}{l}\text { Type of } \\
\text { recurrence }\end{array}$ & $\begin{array}{l}\text { Treatment for } \\
\text { recurrence }\end{array}$ \\
\hline A & $\mathrm{M} / 64$ & Sigmoid & 13 & EMR & Piecemeal & 0 & No & 7 & $\begin{array}{l}\text { Local recurrence } \\
\text { at endoscopic } \\
\text { resection site }\end{array}$ & $\begin{array}{l}\text { Re-endoscopic } \\
\text { resection }\end{array}$ \\
\hline B & $M / 48$ & Descending & 35 & EMR & En bloc & $1(\mathrm{LVI})$ & No & 40 & $\begin{array}{l}\text { Metastatic } \\
\text { recurrence at } \\
\text { distant lymph } \\
\text { nodes }\end{array}$ & $\begin{array}{l}\text { Surgery }+ \\
\text { chemotherapy }\end{array}$ \\
\hline C & $\mathrm{M} / 60$ & Sigmoid & 18 & EMR & Piecemeal & $\begin{array}{l}3 \text { (DSMC, DRM, } \\
\text { LRM) }\end{array}$ & $\begin{array}{l}\text { Yes, anterior } \\
\text { resection }\end{array}$ & 48 & $\begin{array}{l}\text { Metastatic } \\
\text { recurrence at lung }\end{array}$ & Surgery \\
\hline D & $\mathrm{M} / 54$ & Rectum & 12 & ESD & En bloc & $\begin{array}{l}4 \text { (DSMC, DRM, } \\
\text { LVI, PNI) }\end{array}$ & $\begin{array}{l}\text { Yes, low anterior } \\
\text { resection }\end{array}$ & 6 & $\begin{array}{l}\text { Metastatic } \\
\text { recurrence at liver }\end{array}$ & $\begin{array}{l}\text { Surgery and } \\
\text { chemotherapy }\end{array}$ \\
\hline E & M/69 & Ascending & 11 & EMR & En bloc & $\begin{array}{l}4 \text { (DSMC, DRM, } \\
\text { LRM, LVI) }\end{array}$ & $\begin{array}{l}\text { Yes, right } \\
\text { hemicolectomy }\end{array}$ & 33 & $\begin{array}{l}\text { Metastatic } \\
\text { recurrence at } \\
\text { anastomosis site } \\
\text { and adjacent } \\
\text { peritoneum }\end{array}$ & Chemotherapy \\
\hline $\mathrm{F}$ & $\mathrm{M} / 60$ & Rectum & 9 & EMR & En bloc & $\begin{array}{l}3 \text { (DSMC, DRM, } \\
\text { LRM) }\end{array}$ & $\begin{array}{l}\text { Yes, low anterior } \\
\text { resection }\end{array}$ & 89 & $\begin{array}{l}\text { Metastatic } \\
\text { recurrence at lung } \\
\text { and brain }\end{array}$ & $\begin{array}{l}\text { Gamma knife } \\
\text { radiosurgery } \\
\text { and } \\
\text { chemotherapy }\end{array}$ \\
\hline
\end{tabular}

M, male; F, female; EMR, endoscopic mucosal resection; LVI, lymphovascular invasion (+); DSMC, deep submucosal cancer; DRM, deep resection margin involvement (+); LRM, lateral resection margin involvement (+); ESD, endoscopic submucosal dissection; PNI, perineural invasion involvement (+).

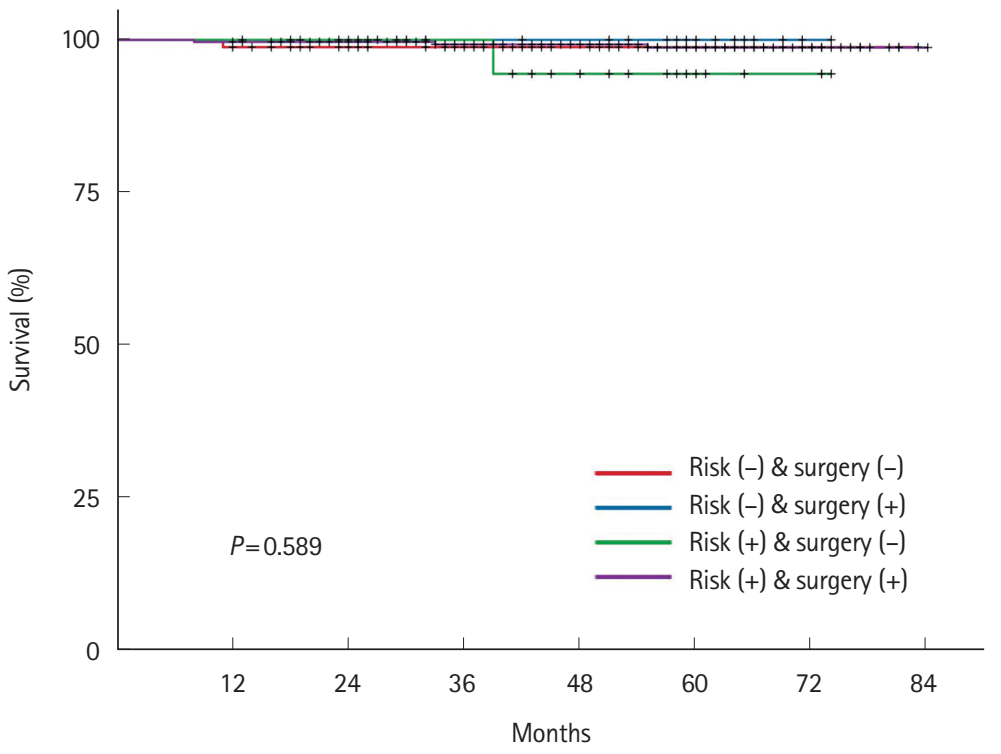

$\begin{array}{lrrrrrrrr}\text { Risk (-) \& surgery (-) } & 98 & 97 & 85 & 72 & 58 & 36 & 13 & 6 \\ \text { Risk (-) \& surgery (+) } & 27 & 27 & 27 & 24 & 23 & 14 & 5 & 4 \\ \text { Risk (+) \& surgery (-) } & 36 & 36 & 28 & 21 & 15 & 8 & 3 & 1 \\ \text { Risk (+) \& surgery (+) } & 336 & 335 & 322 & 287 & 251 & 152 & 63 & 38\end{array}$

Fig. 2. Comparison of recurrence-free survival according to high-risk pathological features and additional surgery. 


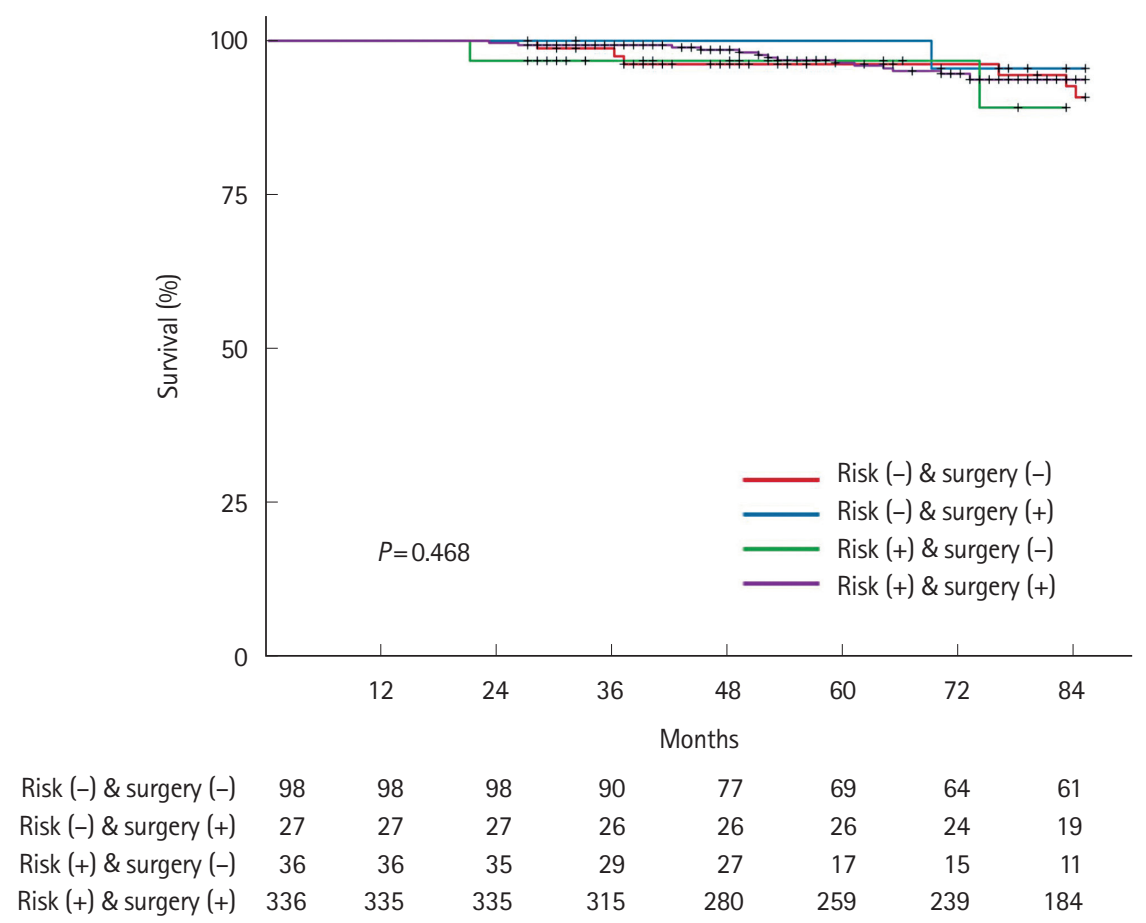

Fig. 3. Comparison of overall survival according to high-risk pathological features and additional surgery.

rence-free survival and overall survival among the 4 groups according to the presence of high-risk pathological features and performance of additional surgery (Figs. 2,3).

\section{Analysis of Additional Surgical Resection Specimen}

Of the 125 patients without high-risk pathological features, no residual cancer or regional lymph node metastasis was found among the 27 surgically treated patients.

There were 19 patients (5.7\%) with residual cancer at the endoscopic resection site and 32 patients $(9.5 \%)$ with regional lymph node metastasis out of 336 surgically treated cases with high-risk pathological features. Four out of these of 336 patients surgically treated with high-risk pathological features had both the residual cancer and the regional lymph node metastasis, resulting in residual cancer or regional lymph node metastasis in 47 (14.0\%) of the 336 cases, and 289 (86.0\%) with no regional lymph node metastasis and residual cancer (Fig. 1). Piecemeal resection, positive lateral resection margin, and positive deep resection margin were more frequent in patients with residual cancer or regional lymph node metastasis (9/47 [19.1\%] vs. $24 / 289$ [8.3\%], $P=0.032 ; 11 / 47$ [23.4\%] vs. $29 / 289$ [10.0\%], $P=0.035 ; 18 / 47$ [38.3\%] vs. 52/289 [18.0\%] $P=0.001$, respectively) (Table 3 ). Positive deep resection margin was also a risk factor for residual cancer and regional lymph node metastasis each, respectively (detailed data not shown).
Regional lymph node metastasis was detected in 32 cases $(8.8 \%)$ of 363 patients undergoing additional surgery. We analyzed the risk of regional lymph node metastasis after additional surgery depending on the number of high-risk pathological features in endoscopic resection specimens. The risk of regional lymph node metastasis also increased as the number of high-risk pathological features increased $(P$ for trend $=0.002)$ (Table 4).

\section{DISCUSSION}

In this large-scale study, which reviewed the specimens of endoscopic resection of 497 patients who were initially diagnosed with SSMC and then analyzed the long-term follow-up patient outcomes, 6 patients recurred during the mean followup period of 91.9 months with the recurrence rate of $1.2 \%$, reassuring the excellence of endoscopic treatment. Of the 125 patients without high-risk pathological features, only 1 local recurrence, of benign adenoma, was seen. Among patients with high-risk pathological features, 5 (1.3\%) distant metastatic recurrences were identified. Only 47 (14.0\%) of the 336 patients with high-risk pathological features who underwent surgery were found of residual cancer or regional lymph node metastasis. There was a high risk of residual cancer or regional lymph node metastasis in surgical specimens when piecemeal resec- 
Table 3. Comparison between Cases with Residual Cancer and/or Positive Regional Lymph Nodes in the Surgical Specimen and Those Without

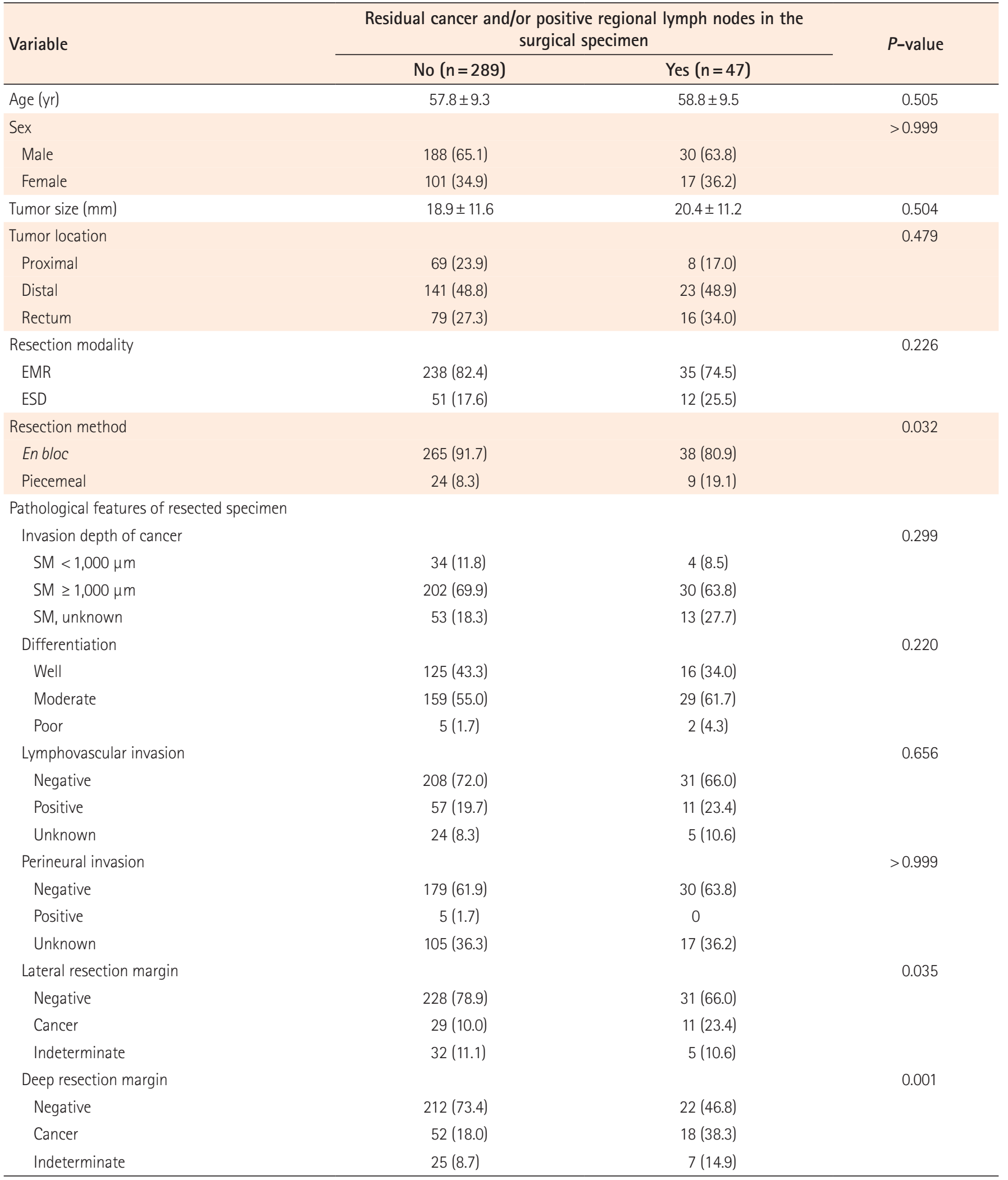

Values are presented as mean \pm SD or number (\%).

EMR, endoscopic mucosal resection; ESD, endoscopic submucosal dissection; SM, submucosa. 
Table 4. Association between the Number of High-Risk Pathological Features and the Risk of Regional Lymph Node Metastasis

\begin{tabular}{|c|c|c|c|}
\hline \multirow{2}{*}{ No. of high-risk pathological features } & \multicolumn{2}{|c|}{ Regional lymph node metastasis } & \multirow{2}{*}{$P$ for trend } \\
\hline & Present & Absent & \\
\hline 0 & $1(3.0)$ & $32(97.0)$ & 0.002 \\
\hline 1 & $9(4.9)$ & 173 (95.1) & \\
\hline 2 & 11 (14.5) & 65 (85.5) & \\
\hline 3 & $10(15.4)$ & $55(84.6)$ & \\
\hline 4 & $1(14.3)$ & $6(85.7)$ & \\
\hline
\end{tabular}

Values are presented as number (\%). List of high-risk pathological features: invasion depth, differentiation, deep resection margin, lateral resection margin, lymphovascular invasion, perineural invasion.

tion was performed or endoscopic resection specimen showed cancer involvement at the resection margin. In addition, interestingly, we found that the risk of regional lymph node metastasis increased proportionally as the number of high-risk pathological features increased in endoscopic resection specimens, which is a novel finding of our study.

Previous studies examining the clinical course after the treatment of early colorectal cancer reported recurrence rates of $0 \%-2.3 \%$ after endoscopic resection for low-risk $\mathrm{T} 1$ cancers, $4.4 \%-20 \%$ after endoscopic resection for high-risk T1 cancer, and $1.4 \%-5.6 \%$ after surgical resection for high-risk T1 cancer. ${ }^{12,21-26}$ In our study, which investigated the patients who underwent endoscopic resection at first with the estimation of SSMC the overall recurrence rate was $1.2 \%$. The recurrence rate was $0.8 \%$ in the low-risk group (1/125), and $1.2 \%$ in the high-risk group with additional surgery, similar with that of the previous studies. In our study, the recurrence rate of $2.8 \%$ in the high-risk group with endoscopic resection and without surgical resection was slightly lower than that of the previous study, owing to the small number of patients in this group, being only 36 .

The reported recurrence rate after endoscopic resection of high-risk submucosal cancer is not so low as $4.4 \%-20 \%$ unless surgery is performed. Additional surgery is therefore recommended. ${ }^{12,13,21-27}$ However, residual cancer or regional lymph node metastasis is not always found in surgical specimens after additional surgery. In our study, residual cancer and/or regional lymph node metastasis were found only in 47 (14.0\%) of 336 surgically performed cases due to high-risk pathological features. This finding suggests that even with high-risk pathological features in endoscopic resection specimens, $86 \%$ of patients had no residual lesions and therefore may not need to undergo additional surgery. Thus, we suggest that if patients with high-risk pathological features can be catego- rized into patients with a high risk of residual cancer or regional lymph node metastasis by the more accurate method clarified through further study, this may be ideal for more effective surgery. In our study, piecemeal resection and cancer involvement at the resection margins were significantly associated with residual cancer or regional lymph node metastasis identified in surgical specimens. Piecemeal resection has a high risk of incomplete resection and is likely to leave residual lesions. In fact, the local recurrence rate after piecemeal resection for a large colorectal neoplasm has been reported to be $0 \%-55 \% .{ }^{28-31}$ In addition, positive resection margins are also suggestive of residual lesions, and piecemeal resection and positive resection margins suggest that lesions are large and invasion depth of cancer is considerably deep. Large, deeply invasive cancers are more likely to have regional lymph node metastasis; ${ }^{7,9,32,33}$ therefore, if endoscopic resection is performed because of suspected SSMC and high-risk pathological features are seen in the resected specimen, additional surgery should be performed. However, if it is difficult to decide to perform additional surgery due to such reasons as comorbidity and old age, strategies for further active surgery can be considered cautiously in cases with additional risk factors such as piecemeal resection and/or positive resection margin.

In several studies of pathologic risk factors predicting regional lymph node metastasis, some high-risk pathological features such as lymphovascular invasion have been reported to have a greater impact on metastasis than other factors, such as poor differentiation. ${ }^{13,34,35}$ On the other hand, the number as well as characteristics of pathological risk factors may be associated with regional lymph node metastasis risk. Backes et al. ${ }^{36}$ developed the LASSO (Least Absolute Shrinkage and Selection Operator) model to calculate the probability of pedunculated $\mathrm{Tl}$ cancer metastasis by inputting the presence or absence of various pathologic risk factors. Our study also con- 
firmed a positive correlation in the risk of regional lymph node metastasis as the number of high-risk pathological features increased. Therefore, if multiple high-risk pathological features are found after endoscopic resection with suspicion of SSMC, it is advisable to recommend additional surgery more strongly than if one has a single high-risk pathological feature. We think that it is necessary to carry out a large-scale multicenter study in order to estimate the regional lymph node metastasis risk according to the number of high-risk pathological features. In addition, such large, multicenter studies may establish a reliable predictive model incorporating not only pathological risk features but also technical features related to endoscopic procedures, which can predict the risk of residual cancer and/or lymph node metastasis with high accuracy.

In the present study, $51.1 \%$ of suspected SSMC were actually DSMC (Table 1). We suggest endoscopic prediction of SSMC was not accurate although we used NBI and/or chromoscopy to assess the invasion depth. We also suggest there could be possible overuse of endoscopic resection in cases which were not considered as SSMC with high confidence. Further effort to assess the invasion depth precisely before endoscopic resection should be made to avoid unnecessary surgery.

Our study has several limitations. First, not all patients had formalized follow-up schedules and follow-up examinations, and some patients did not reach a 5-year follow-up period to determine whether they are cured. Second, there is a difference in endoscopy models and ancillary apparatus types because the period of registration extended from 1996 to 2015. Furthermore, endoscopic pictures were absent in some old cases and we could not investigate the morphology (pedunculated vs. sessile vs. flat) of suspected SSMC cases. Therefore, we could not analyze the recurrence rate according to cancer morphology. Third, submucosal invasion depth of cancer was pathologically diagnosed as SM1, SM2, and SM3 until the mid 2000s, whereas, since the late 2000s, it was diagnosed using absolute measurements. Likewise, we could not investigate tumor budding status in this study because the importance of tumor budding was not introduced widely in clinical practice in late 1990s and early 2000s. Fourth, although total number of patients was high, numbers of patients with each high-risk pathological feature and residual cancer in surgical specimen were small (poorly differentiated adenocarcinoma only in 2 $[4.3 \%]$ and perineural invasion in $0[0 \%]$ surgical specimen). This could be made the results negative. In addition, the small number of recurred cases may also have made identification of reliable risk factors difficult. Despite these limitations, we believe that our study shows the clinical reality of high-risk pathological features found after endoscopic resection of suspected SSMC and the frequency which residual cancer or lymph node metastasis is found in the patients with high-risk pathological features who underwent surgery after endoscopic resection.

In conclusion, residual cancer or regional lymph node metastasis was present in $14.0 \%$ of the cases undergoing surgery because of the high-risk pathological features. Conversely, in $86.0 \%$ of patients, residual cancer or regional lymph node metastasis was not seen, raising a question about whether surgery would have been necessary. Nonetheless, currently, additional surgery should be performed in patients whose surgical specimen shows high-risk pathological features because there are no better predictive methods for remnant cancer than the histological findings of surgical specimen and the surgical mortality of elective colectomy is only about $1 \%$. Further large, multicenter studies on other predictors of residual lesions are necessary for establishing optimized strategies to quantify and validate the risk of residual lesions.

\section{FINANCIAL SUPPORT}

The authors received no financial support for the research, authorship, and/or publication of this article.

\section{CONFLICT OF INTEREST}

No potential conflict of interest relevant to this article was reported.

\section{AUTHOR CONTRIBUTION}

Conception and design: Byeon JS. Analysis, interpretation of the data, and drafting of the article: Choi YS, Kim WS, Byeon JS. Critical revision of the article for important intellectual content: Hwang SW, Park SH, Yang DH, Ye BD, Myung SJ, Yang SK, Byeon JS. Acquisition of data: Choi YS, Kim WS. Approval of final manuscript: all authors.

\section{ORCID}

Choi YS

Kim WS

Hwang SW

Park SH https://orcid.org/0000-0002-8257-3528 https://orcid.org/0000-0001-9545-0140 https://orcid.org/0000-0002-6981-7575 https://orcid.org/0000-0002-5366-5749 
Yang DH

Ye BD

Myung SJ

Yang SK

Byeon JS https://orcid.org/0000-0001-7756-2704

https://orcid.org/0000-0001-6647-6325

https://orcid.org/0000-0003-0585-4016

https://orcid.org/0000-0003-2772-2575

https://orcid.org/0000-0002-9793-6379

\section{REFERENCES}

1. Wong MC, Ding H, Wang J, Chan PS, Huang J. Prevalence and risk factors of colorectal cancer in Asia. Intest Res 2019;17:317329.

2. Hong SN. Genetic and epigenetic alterations of colorectal cancer. Intest Res 2018;16:327-337.

3. Bevan R, Rutter MD. Colorectal cancer screening: who, how, and when? Clin Endosc 2018;51:37-49.

4. Robertson DJ, Lee JK, Boland CR, et al. Recommendations on fecal immunochemical testing to screen for colorectal neoplasia: a consensus statement by the US Multi-Society Task Force on Colorectal Cancer. Gastrointest Endosc 2017;85:2-21.

5. Rex DK, Boland CR, Dominitz JA, et al. Colorectal cancer screening: recommendations for physicians and patients from the U.S. Multi-Society Task Force on Colorectal Cancer. Gastroenterology 2017;153:307-323.

6. Kim TJ, Kim ER, Hong SN, Kim YH, Chang DK. Current practices in endoscopic submucosal dissection for colorectal neoplasms: a survey of indications among Korean endoscopists. Intest Res 2017;15:228-235.

7. Kitajima K, Fujimori T, Fujii S, et al. Correlations between lymph node metastasis and depth of submucosal invasion in submucosal invasive colorectal carcinoma: a Japanese collaborative study. J Gastroenterol 2004;39:534-543.

8. Beaton C, Twine CP, Williams GL, Radcliffe AG. Systematic review and meta-analysis of histopathological factors influencing the risk of lymph node metastasis in early colorectal cancer. Colorectal Dis 2013;15:788-797.

9. Bosch SL, Teerenstra S, de Wilt JH, Cunningham C, Nagtegaal ID. Predicting lymph node metastasis in pT1 colorectal cancer: a systematic review of risk factors providing rationale for therapy decisions. Endoscopy 2013;45:827-834.

10. Mou S, Soetikno R, Shimoda T, Rouse R, Kaltenbach T. Pathologic predictive factors for lymph node metastasis in submucosal invasive (T1) colorectal cancer: a systematic review and meta-analysis. Surg Endosc 2013;27:2692-2703.

11. Ueno H, Mochizuki H, Hashiguchi Y, et al. Risk factors for an adverse outcome in early invasive colorectal carcinoma. Gastroenterology 2004;127:385-394.

12. Kim JB, Lee HS, Lee HJ, et al. Long-term outcomes of endoscopic versus surgical resection of superficial submucosal colorectal cancer. Dig Dis Sci 2015;60:2785-2792.

13. Watanabe T, Muro K, Ajioka Y, et al. Japanese Society for Cancer of the Colon and Rectum (JSCCR) guidelines 2016 for the treatment of colorectal cancer. Int J Clin Oncol 2018;23:1-34.

14. Sano Y, Tanaka S, Kudo SE, et al. Narrow-band imaging (NBI) magnifying endoscopic classification of colorectal tumors proposed by the Japan NBI Expert Team. Dig Endosc 2016;28: 526-533.

15. Hayashi N, Tanaka S, Hewett DG, et al. Endoscopic prediction of deep submucosal invasive carcinoma: validation of the narrow-band imaging international colorectal endoscopic (NICE) classification. Gastrointest Endosc 2013;78:625-632.

16. Puig I, López-Cerón M, Arnau A, et al. Accuracy of the narrow-band imaging international colorectal endoscopic classification system in identification of deep invasion in colorectal polyps. Gastroenterology 2019;156:75-87.

17. Backes Y, Moss A, Reitsma JB, Siersema PD, Moons LM. Narrow band imaging, magnifying chromoendoscopy, and gross morphological features for the optical diagnosis of $\mathrm{T} 1$ colorectal cancer and deep submucosal invasion: a systematic review and meta-analysis. Am J Gastroenterol 2017;112:54-64.

18. Park J, Kim HG, Jeong SO, et al. Clinical outcomes of positive resection margin after endoscopic mucosal resection of early colon cancers. Intest Res 2019;17:516-526.

19. Huh JW, Kim HR, Kim YJ. Lymphovascular or perineural invasion may predict lymph node metastasis in patients with $\mathrm{T} 1$ and T2 colorectal cancer. J Gastrointest Surg 2010;14:10741080.

20. Betge J, Pollheimer MJ, Kornprat P, Rehak P, Vieth M, Langner C. Perineural invasion is a strong and independent predictor of lymph node involvement in colorectal cancer. Dis Colon Rectum 2011;54:e273.

21. Ikematsu H, Yoda Y, Matsuda T, et al. Long-term outcomes after resection for submucosal invasive colorectal cancers. Gastroenterology 2013;144:551-559.

22. Yoda Y, Ikematsu H, Matsuda T, et al. A large-scale multicenter study of long-term outcomes after endoscopic resection for submucosal invasive colorectal cancer. Endoscopy 2013;45: 718-724.

23. Heo J, Jeon SW, Jung MK, Kim SK, Kim J, Kim S. Endoscopic resection as the first-line treatment for early colorectal cancer: comparison with surgery. Surg Endosc 2014;28:3435-3442.

24. Yoshii S, Nojima M, Nosho K, et al. Factors associated with risk for colorectal cancer recurrence after endoscopic resection of 
T1 tumors. Clin Gastroenterol Hepatol 2014;12:292-302.

25. Asayama N, Oka S, Tanaka S, et al. Long-term outcomes after treatment for $\mathrm{T} 1$ colorectal carcinoma. Int J Colorectal Dis 2016;31:571-578.

26. Nam MJ, Han KS, Kim BC, et al. Long-term outcomes of locally or radically resected $\mathrm{T} 1$ colorectal cancer. Colorectal Dis 2016; 18:852-860.

27. Ferlitsch M, Moss A, Hassan C, et al. Colorectal polypectomy and endoscopic mucosal resection (EMR): European Society of Gastrointestinal Endoscopy (ESGE) clinical guideline. Endoscopy 2017;49:270-297.

28. Moss A, Bourke MJ, Williams SJ, et al. Endoscopic mucosal resection outcomes and prediction of submucosal cancer from advanced colonic mucosal neoplasia. Gastroenterology 2011; 140:1909-1918.

29. Seo M, Song EM, Kim GU, et al. Local recurrence and subsequent endoscopic treatment after endoscopic piecemeal mucosal resection with or without precutting in the colorectum. Intest Res 2017;15:502-510.

30. Woodward TA, Heckman MG, Cleveland P, De Melo S, Raimondo M, Wallace M. Predictors of complete endoscopic mucosal resection of flat and depressed gastrointestinal neoplasia of the colon. Am J Gastroenterol 2012;107:650-654.

31. Khashab M, Eid E, Rusche M, Rex DK. Incidence and predictors of "late" recurrences after endoscopic piecemeal resection of large sessile adenomas. Gastrointest Endosc 2009;70:344349.

32. Kikuchi R, Takano M, Takagi K, et al. Management of early invasive colorectal cancer: risk of recurrence and clinical guidelines. Dis Colon Rectum 1995;38:1286-1295.

33. Nascimbeni R, Burgart LJ, Nivatvongs S, Larson DR. Risk of lymph node metastasis in T1 carcinoma of the colon and rectum. Dis Colon Rectum 2002;45:200-206.

34. ASGE Standards of Practice Committee, Fisher DA, Shergill $\mathrm{AK}$, et al. Role of endoscopy in the staging and management of colorectal cancer. Gastrointest Endosc 2013;78:8-12.

35. Labianca R, Nordlinger B, Beretta GD, et al. Early colon cancer: ESMO clinical practice guidelines for diagnosis, treatment and follow-up. Ann Oncol 2013;24 Suppl 6:vi64-vi72.

36. Backes Y, Elias SG, Groen JN, et al. Histologic factors associated with need for surgery in patients with pedunculated T1 colorectal carcinomas. Gastroenterology 2018;154:1647-1659. 